\title{
Herbs: A Way to Enhance Functionality of Traditional Dairy Products
}

\author{
Basant Bais ${ }^{1 *}$,Lokesh Tak ${ }^{2}$ and Jorawar Singh ${ }^{2}$ \\ ${ }^{1}$ College of Veterinary and Animal Science, Bikaner, India \\ ${ }^{2}$ College of Veterinary and Animal Science, Bikaner, India
}

Submission: May 21, 2018; Published: July 02, 2018

*Corresponding author: BasantBais,Head, Department of Livestock Products Technology, College of Veterinary and Animal Science, Bikaner, RAJUVAS, India, Email: basantbais@gmail.com

Keywords: Dairy Products; Natural health; Ghee; Herbs; Cheese; Ayurveda; Butter oil; Nutrition;Dahi;Milk; Literature; Antioxidants; Ferulic acid;Tea catechins;Oleuropein;Ellagic acid; Phenolic compounds

\section{Introduction}

The functionalfoods promote health beyond supplying basic nutrition. As a result, the functional foods are gaining popularity throughout the world. The growing consumer demand along with industry interest states that there is a great scope for functional foods in India.A huge amount of milk produced in India is utilized for manufacturing of traditional dairy products [1]. Indian traditional dairy products have a significant demand and their domestic markets are well established. However, to compete and to sustain with the ever-increasing functional food market, Indian dairy industry should find ways to induce or to improve the functionality in traditional dairy products.Herbs and their extracts have a long history of usage as natural remedies for curing many health-related complications. Herbs have also found their usage in culinary purposes and some of them have been reported for their use in cheese, yoghurt and other food products. Since 1960, there has been an increased interest in "natural health" and it has propelled the consumption of natural remedies i.e. herbs and their preparations. A considerable portion of today's functional food market consists of herbal supplemented functional foods [2].

Ayurveda, Indian traditional medicinal literature, has prescribed several ways in which the medicinal benefits of herbs could be conveyed via certain foods as carriers. More than 50 medicated ghee formulations made with incorporating different herbal preparations were reported in Ayurveda. However, there is a very little or no literature reported regarding supplementation of herbs into other Indian dairy products to improve their functionality. In the recent past, traditional dairy products have received special attention from the $R \& D$ institutions. Research has been carried out to induce and/or to improve the functionality of many Indian dairy products. Developments in the manufacture Indian dairy products with improved functionality, especially herbal supplemented Indian dairy products are depicted here.

\section{Application of Herbs and Herbal Nutraceuticals in Milk and Milk Products}

\section{Fat Rich Dairy Products}

Herbs contain high amounts of phenolic compounds which possess antioxidant properties. The natural antioxidant properties of herbs have made their use in the formulation of functional foods specifically targeted for the people suffering from cardio vascular diseases [3]. The antioxidant properties of herbs also led their use into fat rich dairy products for retarding auto-oxidation there by prolonging the shelf-life. Moreover, it was found that the artificial antioxidants, like BHT (butylated hydroxytoluene) or BHA (butylated hydroxyanisole) are not safe for human consumption (suspected to have carcinogenic activity). On the other hand, increasing sensitivity of consumers to synthetic ingredients as well as their increasing awareness about the effect of diet on their health contributed to the increasing trend to use natural additives like herbal extracts for the stabilization of fat rich dairy foods like ghee, butter oil, butter etc. Sage (Salvia officinalis) and Rosemary (Rosmarinus officinalis) extracts are the most widely used for this purpose [4]. These extracts have antioxidant activity many times stronger than synthetic antioxidants like BHA or BHT [5].

Milk fat, particularly ghee has the characteristics to absorb all the medicinal properties of the herbs with which it is fortified, without losing its own attributes. About 60 medicated ghee 
preparations used for the treatment of various diseases were reported in Ayurvedicliterature [6].Recently, Arjuna gheewas developed at NDRI, Karnal by incorporating functional attributes of Terminalia arjuna for providing beneficial effects against cardiovascular diseases and the product was more stable to oxidative deterioration as compared to control ghee[7]. Unlike in case of medicated ghee preparations, Arjunaghee can be replaced with normal ghee in the daily diet. Pawar et al. [8] has successfully increased the oxidative stability of ghee by incorporating the alcoholic and aqueous extracts of Satavariherb.

Research evidence supporting the health benefits of herbal ghee preparations is scanty. In a clinical study on antiasthamine effects of vasaghee (ghrit), Prasher[9] reported that oral ingestion of vasa ghee was beneficial in reducing the risk of asthama. There was marked improvement in $92.59 \%$ cases within 21 days of study period. HPTLC studies have shown that vasicinone, an antiasthamine agent present in Adhatodavasica was responsible for antiasthamine effects of vasa ghee. The authors have also reported that vasa ghee consumption also had an additional benefit in reducing serum cholesterol level by $30.16 \%$. Pharmaco clinical studies showed that Panchtikta ghee(ghrit) prepared with different methods was beneficial in reducing the cardiovascular diseases [6]. A thorough study on the bioactive components of herbs and effect of different processing conditions on them during ghee preparation could lead us to diversify the usage of ghee in a well-organized commercial way.

\section{Dahi and Lassi}

Aloe vera, an herb of the Liliaceae family has a long and illustrious history dating from biblical times and given a high ranking as an all-purpose herbal plant. Scientific investigations on Aloe verahave gained more attention over the last several decades due to its reputable medicinal properties [10]. Lassi, a ready-to-serve traditional fermented milk beverage has got wide popularity in India as well as in overseas markets. Sweet lassi with its characteristic sweet and slightly sour taste can be used as a food carrier for herbal bioactives like Aloe verajuice. Hussain et al. [2] has developed functional lassi using the herb Aloe vera(Aloe barbadensis Miller). A culture combination containing NCDC 60 and Lactobacillusparacseisspparacasei L at an inoculum rate of 1 percent was used for functional lassi preparation. Animal study of functional lassi revealed that it has better immune protective effects compared to control lassi. Recently, Pal et al. [11] also supplemented Aloe verajuice into lassi to enhance its health benefits. The authors have reported that supplementation of Aloe verajuice at $15 \%$ level into lassi has obtained optimum sensory scores.

Herbal supplemented probiotic dahi using the herb Aloe barbadensis Miller was also prepared by Hussain et al.[12]. The authors have reported that Aloe verasupplementation has supported the growth of probiotic strain Lactobacillus paracseisspparacasei $\mathrm{L}$ in dahi. The probiotic viability was more than $7 \log \mathrm{cfu} / \mathrm{ml}$ during 12 days storage period.

\section{Sandesh}

Sandesh is a very popular heat-desiccated product of coagulated milk protein mass called chhana. About $80 \%$ of chhana produced in Kolkata (West Bengal, India) is converted into sandesh [13]. Incorporation of herbs into these kinds of highly demanded dairy products will improve the health status of the consumers. Bandyopadhyay et al. [14] incorporated herbs such as turmeric (Curcuma longa L.), coriander (Coriandrum sativum L.), curry leaf (Murrayakoenigii L.), spinach (Spinacia oleracea) and aonla (Emblica officinalis), separately as a paste, at the $10 \%$ level into Sandesh to induce the antioxidant properties into the product. The antioxidative levels of these herbs were compared with the synthetic antioxidants TBHQ and BHA: BHT (1:1) at 100 and $200 \mathrm{mg} / \mathrm{kg}$ levels. The authors have reported that the total antioxidative status of herbal sandesh was lower than samples with TBHQ but like those with $200 \mathrm{mg} / \mathrm{kg}$ BHA: BHT (1:1). The authors have also reported that the use of coriander herb with its antimicrobial and antioxidant properties increased the shelf-life of herbalsandesh up to 8 days at $\left(30 \pm 1^{\circ} \mathrm{C}\right)$ and 30 days at $\left(7 \pm 1^{\circ} \mathrm{C}\right)$ when compared with the remaining samples.

\section{Shrikhand}

Shrikhand is a semi-soft, sweetish-sour, whole milk product prepared from lactic fermented curd [15]. Shrikhandis prepared by admixing of sugar in required quantities with strained dahi or concentrated dahi. Being a sweetish-sour and semi soft product it can easily harbour herbs/herbal extracts without undergoing significant quality changes.Landge et al.[16] successfully prepared shrikhand using Ashwagandha herb powder as an additive. The authors have found that addition of $0.5 \%$ Ashwagandha powder to shrikhand has improved the organoleptic quality and the product was remained acceptable up to 52 days at refrigerated temperatures.

Other Possible Uses of Herbs to Improve the Functionality of Indian Dairy Products

Most of the Indian traditional dairy products contain high amount moisture content besides harbouring valuable nutrients. The high moisture content of these dairy products will favour the growth of microorganisms leading to their spoilage. Phenolic compounds of herbs are a good alternative for the synthetic antimicrobial agents used in food industry. Phenolic compounds namely, ferulic acid, tea catechins, oleuropein, ellagic acid and p-coumaric acid have been reported to inhibit the growth of pathogenic bacteria (Salmonella enteritidis, Staphylococcus aureus, Listeria monocytogenes) and fungi [17]. These antimicrobial properties herbs can be effectively utilized to control the growth of unwanted/spoilage and pathogenic microbes in Indian dairy products. Oleuropein derived from 
Olive tree has been reported to markedly inhibit the production of aflotoxins [18]. This property of oleuropein could be advantageous in products like chhana and paneer where the growth of moulds leading to mycotoxins production may present health risk $[19,20]$.

\section{Conclusion}

Herbs are considered as nature's gift to human beings as they can prevent and cure many illnesses. Herbs harbor a wide variety of functional components which can perform wide range of biological functionalities. In recent past, research regarding functionality of herbal components, toxicology and their use in food products has been the matter of interest. However, depending upon the concentration and type, the incorporation of herbs into food products may have certain undesirable effects on their sensory, physico-chemical and textural properties which in turn could affect their overall acceptability. Presently, the herbal gheebeing marketed in the global market is mostly sold as medicine (medicinal ghee), which is associated with typical flavour, bitter or pungent taste and a dark colour. Such therapeutic preparations are therefore not acceptable for routine use. Incorporation of these nutraceuticals into food systems may therefore calls for technological modifications/alterations so that the sensory quality of the final product remains unaltered.Furthermore, very limited information is available for ascertaining the residual levels of these functional components in herbal food preparations. Interactions of herbal and food constituents on human health must be studied thoroughly. More research should be directed towards the effect of processing conditions on the bioavailability of functional components in the herbs so that the processes will be designed in such a way that little or no damage will occur to the functional components during their incorporation into food matrix.

\section{References}

1. Pal D, Raju PN (2007) Indian traditional dairy products: an overview In Sovenir of International conference on Traditional dairy foods held at National Dairy Research Institute. Karnal from November p: 14-17.

2. Hussain SA, Sharma P, Singh RRB (2011) Functional Dairy Foods - An overview. In Souvenir of International conference on functional dairy foods held during Nov 16-19 at Karnal, India, p: 7-12.

3. Najgebauer-Lejko D, Grega T, Sady M, Domagała J (2009) The quality and storage stability of butter made from sour cream with addition of dried sage and rosemary. Biotechnology in Animal Husbandry 25(5-6): 753-761.

4. Özcan M (2003) Antioxidant activity of rosemary, sage and sumac extracts and their combinations on stability of natural peanut oil. Journal of Medicinal Food 6(3): 267-270.

5. Estévez M, Ramirez R, Ventanas S, Cava R (2007) Sage and rosemary essential oils versus BHT for the inhibition of lipid oxidative reactions in liver pâté. LWT: Food Science and Technology 40: 58-65.
6. Pandya NC, Kanawjia SK (2002) Ghee: A Traditional Nutraceutical. Indian Dairyman 54(10): 67-75.

7. Rajanikant and Patil GR (2005) Development of process for herbal ghee. NDRI News 10(2).

8. Pawar N, Arora S, Singh RRB, Wadhwa, BK (2012) The effects of Asparagus racemosus (shatavari) extract on oxidative stability of ghee, in relation to added natural and synthetic antioxidants. International Journal of Dairy Technology 65(2): 293-299.

9. Prasher R (1999) Standardization of Vasa Ghrita and its extract form and their comparative pharmaco-clinical study with special reference to Swasa Roga (Asthma). MD Thesis, Gujarat Ayurved University, Jamnagar, India.

10. Hussain SA, Raju PN, Singh RRB, Patil GR (2015) Potential herbs and herbal nutraceuticals: Food applications and interactions with food components. Critical Reviews in Food Science and Nutrition 55(1): 94122.

11. Pal ST, Santosh K, Swati S (2012) Development of lassi containing Aloe vera juice and its quality characteristics. Journal of Dairying Foods \& Home Sciences 31(1): 1-4.

12. Singh RRB, Hussain SA (2011) Application of herbs in development of functional milk and milk products. In compendium of National Training Programme on Basic and Applied Approaches in Designing of Dairy based Nutraceuticals and Functional Foods. 18-2 $7^{\text {th }}$ July, 2011, NDRI, Karnal, India, pp: 19-24.

13. Aneja RP, Mathur BN, Chandan RC, Banerjee AK (2002) Technology of Indian milk products. A Dairy India Publication, New Delhi, India.

14. Bandyopadhyay M, Chakraborty R, Raychaudhuri U (2007) Incorporation of herbs into sandesh, an Indian sweet dairy product, as a source of natural antioxidants. International Journal of Dairy Technology 60(3): 228-233.

15. De S (1980) Shrikhand in Outlines of Dairy Technology. Oxford Publishers, New Delhi, India, pp: 410-412.

16. Landge UB, Pawar BK, Choudhari DM (2011) Preparation of shrikhand using Ashwagandha powder as additive. Journal of Dairying Foods \& Home Sciences 30(2): 79-84.

17. Schaller F, Rahalison L, Islam N, Potterat O, Hostettmann K, StoeckliEvans H, Mavi S (2000) A new potent antifungal 'quinone methide' diterpene with a cassane skeleton from Bobgunnia madagascariensis. Helvetica Chimica Acta 83: 407-413.

18. Bullerman H, Gourma LB (1987) Effects of oleuropein on the growth and aflatoxin production by Aspergillus parasiticus. Zeitschrift fur Lebensmittel-Untersuchung und-Forschung 20: 226-228.

19. Jarvis B (1983) Mould and mycotoxins in mouldy cheeses. Microbiologie Aliments Nutr 1: 187-191.

20. Singh RRB, Sharma P, Hussain SA (2012) Product diversification opportunities and emerging technologies for the Indian dairy industry. In Souvenir of National seminar on Dairying in Eastern India: Challenges and Opportunities organized by Indian Dairy Association (EZ) Bihar State Chapter, Patna, during 15-16 ${ }^{\text {th }}$ Apr, 2012 at Patna, Bihar, India, pp: 52-60. 
(C) This work is licensed under Creative (C) Commons Attribution 4.0 License DOI: 10.19080/JDVS.2018.06.555689

\section{Your next submission with Juniper Publishers} will reach you the below assets

- Quality Editorial service

- Swift Peer Review

- Reprints availability

- E-prints Service

- Manuscript Podcast for convenient understanding

- Global attainment for your research

- Manuscript accessibility in different formats ( Pdf, E-pub, Full Text, Audio)

- Unceasing customer service

Track the below URL for one-step submission https://juniperpublishers.com/online-submission.php 